OPEN ACCESS

Edited by:

Thomas A. Ficht,

Texas A\&M University, USA

Reviewed by:

Parish Paymon Sedghizadeh, University of Southern California, USA

Edvaldo Antonio Ribeiro Rosa,

The Pontifical Catholic University of

Paraná, Brazil

*Correspondence: Letícia M. Gonçalves lets.mg@gmail.com

Received: 02 December 2015 Accepted: 16 June 2016

Published: 28 June 2016

Citation:

Madeira PLB, Carvalho LT, Paschoal MAB, de Sousa EM, Moffa EB, da Silva MAdS, Tavarez RdJR and Gonçalves LM (2016) In vitro Effects of Lemongrass Extract on Candida albicans Biofilms,

Human Cells Viability, and Denture

Surface.

Front. Cell. Infect. Microbiol. 6:71. doi: 10.3389/fcimb.2016.00071

\section{In vitro Effects of Lemongrass Extract on Candida albicans Biofilms, Human Cells Viability, and Denture Surface}

\author{
Petrus L. B. Madeira ${ }^{1}$, Letícia T. Carvalho ${ }^{1}$, Marco A. B. Paschoal ${ }^{1}$, \\ Eduardo M. de Sousa ${ }^{2}$, Eduardo B. Moffa ${ }^{1}$, Marcos A. dos Santos da Silva ${ }^{1}$, \\ Rudys de Jesus Rodolfo Tavarez ${ }^{1}$ and Letícia M. Gonçalves ${ }^{1 *}$ \\ ${ }^{1}$ Post-Graduate Program in Dentistry, CEUMA University, São Luis, Brazil, ${ }^{2}$ Post-Graduate Program in Parasite Biology, \\ CEUMA University, São Luis, Brazil
}

The purpose of this study was to investigate whether immersion of a denture surface in lemongrass extract (LGE) has effects on C. albicans biofilms, human cell viability and denture surface. Minimal inhibitory concentration (MIC) and minimal fungicidal concentration (MFC) were performed for LGE against C. albicans. For biofilm analysis, discs were fabricated using a denture acrylic resin with surface roughness standardization. C. albicans biofilms were developed on saliva-coated discs, and the effects of LGE at MIC, 5XMIC, and 10XMIC were investigated during biofilm formation and after biofilm maturation. Biofilms were investigated for cell counting, metabolic activity, and microscopic analysis. The cytotoxicity of different concentrations of LGE to peripheral blood mononuclear cells (PBMC) was analyzed using MTT. The effects of LGE on acrylic resin were verified by measuring changes in roughness, color and flexural strength after 28 days of immersion. Data were analyzed by ANOVA, followed by a Tukey test at a $5 \%$ significance level. The minimal concentration of LGE required to inhibit C. albicans growth was $0.625 \mathrm{mg} / \mathrm{mL}$, while MFC was $2.5 \mathrm{mg} / \mathrm{mL}$. The presence of LGE during biofilm development resulted in a reduction of cell counting $(p<0.05)$, which made the MIC sufficient to reduce approximately $90 \%$ of cells $(p<0.0001)$. The exposure of LGE after biofilm maturation also had a significant antifungal effect at all concentrations $(p<0.05)$. When compared to the control group, the exposure of PBMC to LGE at MIC resulted in similar viability $(p>0.05)$. There were no verified differences in color perception, roughness, or flexural strength after immersion in LGE at MIC compared to the control ( $p>0.05$ ). It could be concluded that immersion of the denture surface in LGE was effective in reducing $\mathrm{C}$. albicans biofilms with no deleterious effects on acrylic properties at MIC. MIC was also an effective and safe concentration for use.

Keywords: human cells, C. albicans, lemongrass extract, biofilm 


\section{INTRODUCTION}

Candida albicans is the main pathogen responsible for the development of Candida-associated denture stomatitis (CADS), an infection commonly observed in denture wearers (Gendreau and Loewy, 2011). If not treated with appropriate hygiene or antifungal treatments, the yeast cells adhere to the acrylic denture surface and are predominantly organized as biofilms (Krom et al., 2014; Goncalves et al., 2015).

Mechanical brushing is a simple and widely used method of hygiene used to control biofilms in dentures (Tan et al., 2014). However, the visual limitations and poor hand function of some denture wearers (Padilha et al., 2007), in combination with the challenges posed by denture design, can limit biofilm removal (Glass et al., 2010). Although chemical immersion solutions have been recommended as complementary methods to mechanical hygiene (Pellizzaro et al., 2012), it has been observed that these treatments also fail to remove C. albicans biofilms (LucenaFerreira et al., 2013, 2014). In cases where CADS is a persistent infection, applying an antifungal agent becomes a daily routine (e.g., fluconazole and nystatin; Lalla and Dongari-Bagtzoglou, 2014). The drug resistance of C. albicans is one of the major problems in combatting the survival and propagation of biofilm and may ultimately lead to treatment failure (Taff et al., 2013; Ramage et al., 2014).

Considering the current challenges with controlling CADS using conventional therapies, the search for alternative antifungal substances has become a trend in the medical literature (Khan and Ahmad, 2012; Taweechaisupapong et al., 2012; Nett, 2014). In the process of developing new pharmacologically active compounds, plants used in folk medicine represent a rational approach to the quest for drugs (Ahmad and Beg, 2001; Duarte et al., 2005; Rios and Recio, 2005; Vieira et al., 2014). Among these plants, Cymbopogon citratus, an herb known around the world as lemongrass, has been reported to exert potent inhibitory effects against Candida species (Abe et al., 2003; Silva Cde et al., 2008; Irkin and Korukluoglu, 2009; Amornvit et al., 2014; Tadtong et al., 2014). Thus, the application of lemongrass as an effective and easily available antifungal agent could be considered an alternative approach to reducing $C$. albicans biofilms on denture surfaces.

It is important to point out that in most studies, lemongrass susceptibility tests were performed in planktonic cells (Abe et al., 2003; Silva Cde et al., 2008; Irkin and Korukluoglu, 2009; Tyagi and Malik, 2010; Khan and Ahmad, 2012; Amornvit et al., 2014; Boukhatem et al., 2014; Tadtong et al., 2014), while most C. albicans cells in the oral cavity were associated with biofilms. It is known that biofilms differ substantially from planktonic cells, particularly in terms of their higher antifungal resistance (Ramage et al., 2014). In addition, investigations about the safety of lemongrass and its possible effects on the mechanical or physical properties of acrylic surfaces (Moffa et al., 2011; Paranhos Hde et al., 2013; de Sousa Porta et al., 2015) are of the utmost importance in deciding whether this herb is a possible auxiliary treatment for CADS. Thus, the purpose of this study was to investigate whether immersing the denture surface in LGE would have an effect on C. albicans biofilms, human cell viability and denture surfaces.

\section{MATERIALS AND METHODS}

\section{Study Design}

The antifungal activity of LGE against Candida albicans planktonic cells was verified by minimal inhibitory concentration (MIC) and minimal fungicidal concentration (MFC). Discs were fabricated using a denture acrylic resin for biofilm analysis. C. albicans biofilms were developed on saliva-coated discs in specific culture mediums with LGE at MIC, 5XMIC, or 10XMIC (experimental groups) for $72 \mathrm{~h}$ in order to investigate the effects of LGE during biofilm formation. In addition, the effects of LGE on $72 \mathrm{~h}$-mature biofilms were also investigated by immersing them in distilled water (control group) and LGE at MIC, 5XMIC, or 10XMIC (experimental groups) for $8 \mathrm{~h}$. Analyses included cell count, metabolic activity, and microscopic assays. Furthermore, the cytotoxicity effect of different concentrations of LGE on peripheral blood mononuclear cells (PBMC) was analyzed using an MTT assay as well. Substrata measurements were indicated by changes in color, surface roughness, and flexural strength, which were analyzed after 28 days of immersion in LGE. All tests were performed in triplicate on three different days $(N=9)$. Data were analyzed by ANOVA, followed by Tukey's test at $5 \%$ of the significance level.

\section{Vegetal Material \\ Collection and Botanical Identification}

The vegetal material of Cymbopogon citratus (i.e., lemongrass) was grown in the experimental field of the Federal University of Maranhão, São Luís, Maranhão, Brazil. The sample was collected from November 2013 to August 2014. Exsiccate was prepared and sent to the Ático Seabra Herbarium of the Federal University of Maranhão for botanical identification. Exsiccate was prepared and sent to the Herbarium "Atticus Seabra" of the Federal University of Maranhão to botanical identification (plant voucher \#00537).

\section{Preparation of the Extract}

The vegetal material was dried separately in a greenhouse at $37^{\circ} \mathrm{C}$ air circulation for $48 \mathrm{~h}$ then triturated in a cutting mill. The remaining water was evaporated through freeze drying. For $24 \mathrm{~h}$, the dried and crushed lemongrass (200 g) was extracted at room temperature through maceration with ethanol at $70 \%$. That process was repeated four times. The LGE obtained was filtered and then concentrated under reduced pressure in a rotatory evaporator. The dried residue was diluted in sterile saline solution to a final concentration of $200 \mathrm{mg} / \mathrm{mL}$, sterilized through filtration with a $0.22 \mu \mathrm{g} / \mathrm{mL}$ membrane and kept in sterile amber bottles at $4^{\circ} \mathrm{C}$ for testing purposes.

\section{Candida albicans Growth Conditions}

Candida albicans (ATCC 18804) was aerobically cultured from the original broth through incubation in Sabouraud Dextrose Agar (SDA; Difco, Detroit, MI, USA) for $24 \mathrm{~h}$ at $35^{\circ} \mathrm{C}$. A loop of yeast cells was inoculated into a Yeast Nitrogen Base (YNB; 
Difco, Detroit, MI, USA) culture medium, supplemented with $100 \mathrm{mM}$ glucose and aerobically incubated under agitation at $35^{\circ} \mathrm{C}$. During the exponential growth phase (i.e., after $18-20 \mathrm{~h}$ of incubation), the C. albicans cells were washed twice with phosphate-buffered saline (PBS, pH 7.2). Inoculum was prepared in an YNB medium and optically standardized at a mean of $\sim 10^{7}$ cells $/ \mathrm{mL}(O D=0.25$ at $520 \mathrm{~nm})$.

\section{Susceptibility Tests}

The results of MIC and MFC tests were determined using M27A3 standards (CLSI, 2008). For all assays, fluconazole (reference powder; Sigma Aldrich Co., St. Louis, MO, USA) was used as a positive control (Goncalves et al., 2012). A negative control and a solvent (ethanol) control were also used.

\section{Minimal Inhibitory Concentration}

An MIC assay was performed with a microdilution test using a 96-well-culture plate. The stock solutions of LGE were diluted and transferred into the first well and serial dilutions were performed to obtain concentrations in the range of 100-0.19 $\mathrm{mg} / \mathrm{mL}$. The previously prepared C. albicans standard suspension $\left(\sim 10^{7}\right.$ cells $\left./ \mathrm{mL}\right)$ was adjusted in an RPMI 1640 medium so that it contained $\sim 10^{3}$ cells $/ \mathrm{mL}$. It was then added to all wells. The plate was incubated at $37^{\circ} \mathrm{C}$ for $48 \mathrm{~h}$, and MIC was defined as the lowest concentration of LGE that could inhibit visible growth.

\section{Minimal Fungicidal Concentration}

The non-visible growth wells verified in the MIC test were cultured on SDA plates and incubated at $37^{\circ} \mathrm{C}$ for $48 \mathrm{~h}$. MFC was considered to be the lowest concentration of LGE that could kill fungal cells ( $\geq 99 \%$ of fungal death).

\section{Antifungal Activity in Biofilms Discs Fabrication}

Round-shaped discs (10-mm diameter, 2-mm thickness) were fabricated using a water-bath polymethylmethacrylate (PMMA) acrylic resin (VipiCril Plus; VipiCril, São Paulo, Brazil) according to manufacturers' instructions. The discs were prepared using a stainless matrix with standardized dimensions. Processed discs were immersed in distilled water for $48 \mathrm{~h}$ at $37^{\circ} \mathrm{C}$ to allow for the release of residual monomers (Moura et al., 2006). To simulate the inner side of a denture, the disc surfaces were ground in a horizontal polisher (model APL-4; Arotec, São Paulo, Brazil) using progressively smoother aluminum oxide papers $(320,400$, and 600 grit). The surface roughness of all discs was analyzed using a rugosimeter (Mitutoyo Corp., Tokyo, Japan) with an accuracy close to $0.01 \mu \mathrm{m}$ and calibrated at cutoff values of $0.8,2.4 \mathrm{~mm}$ percussion of measure and $0.5 \mathrm{~mm} / \mathrm{s}$. The mean of three measurements for each disc was calculated, and the surface roughness was standardized at $0.31 \pm 0.05 \mu \mathrm{m}$. After these measurements, the discs were ultrasonically cleansed in purified water for $20 \mathrm{~min}$ and disinfected with $1.0 \%$ sodium hypochlorite for $3 \mathrm{~min}$ to remove any contaminants or artifacts.

\section{Biofilm Development}

To mimic the oral cavity, the discs were coated with human salivary pellicles prior to biofilm development. Saliva was collected from a healthy volunteer who provided written formal consent according to a protocol approved by the Ethics Committee in Research of Ceuma University (\#105/2014). Saliva was collected in an ice-chilled polypropylene tube during masticatory stimulation with a flexible film, clarified by centrifugation $\left(10,000 \times \mathrm{g}\right.$ for $5 \mathrm{~min}$ at $\left.4^{\circ} \mathrm{C}\right)$ with the supernatant filter, sterilized, and used immediately.

Under aseptic conditions, each disc was placed in a 24-wellculture plate. An aliquot of saliva was then added to each well. The plate was aerobically incubated for $1 \mathrm{~h}$ at $37^{\circ} \mathrm{C}$ to form the salivary pellicle. Saliva-coated discs were then transferred to a 24-well-culture plate, and a pre-prepared $C$. albicans standard suspension $\left(\sim 10^{7}\right.$ cells $\left./ \mathrm{mL}\right)$ was added to each well and aerobically incubated at $37^{\circ} \mathrm{C}$ for $1.5 \mathrm{~h}$ (adhesion phase). The discs were carefully washed with PBS and transferred to a new 24-well-culture plate containing an YNB $100 \mathrm{mM}$ glucose culture medium for $24 \mathrm{~h}$. At the end of this period, the discs were washed with PBS, and a new fresh medium was added and aerobically incubated for $72 \mathrm{~h}$ at $37^{\circ} \mathrm{C}$.

The effects of LGE in C. albicans biofilms were investigated at two distinct times: while the biofilm was forming and after it matured. In the first step, LGE was added daily to the fresh culture medium at MIC, 5XMIC, or 10XMIC for 3 consecutive days $(72 \mathrm{~h})$ to allow biofilm to develop. The goal of the second step was to verify the effects of LGE in biofilms matured for $72 \mathrm{~h}$ and submit them to the groups cited above for $8 \mathrm{~h}$. The analysis was carried out through biofilm cell counting, metabolic activity, and fluorescence microscopy.

\section{Cell Counting}

For cell counting, biofilm discs were washed twice with PBS and sonicated ( $7 \mathrm{~W}$, for $30 \mathrm{~s}$ ) to allow for disruption of the biofilm structure. Then the sonicated solutions were serially diluted in PBS and plated in triplicate onto SDA. Plates were aerobically incubated for $24 \mathrm{~h}$ at $37^{\circ} \mathrm{C}$, and the yeast cells were counted and converted into cells $/ \mathrm{mL}$ units with the support of a stereomicroscope.

\section{Metabolic Activity}

The metabolic activity was determined with a modified XTT assay protocol (Moura et al., 2006; da Silva et al., 2008). Accordingly, biofilm discs were placed in a 24-well-culture plate with XTT solution (PBS supplemented with $200 \mathrm{mM}$ glucose, $1 \mathrm{mg} / \mathrm{mL}$ XTT, and $0.4 \mathrm{mM}$ menadione), and the plates were protected from light and incubated for $3 \mathrm{~h}$ at $37^{\circ} \mathrm{C}$. Colorimetric changes in the supernatant were analyzed with the support of a spectrophotometer adjusted to $492 \mathrm{~nm}$.

\section{Microscopic Analysis}

The biofilm's structure was evaluated using fluorescence microscopy (Axio Imager Z2; Carl Zeiss, Oberkochen, Germany). The discs of biofilm were washed with PBS twice, stained with SYTO-9 and propidium iodide with the Live/Dead BacLight viability kit (Invitrogen-Molecular Probes, Eugene, OR, USA), incubated for $20 \mathrm{~min}$ at $37^{\circ} \mathrm{C}$ and protected from light. At least five randomly chosen optical fields were examined for each disc using the $63.4 \mathrm{x}$ immersion lens. 


\section{Human Cell Viability}

Peripheral blood mononuclear cells (PBMCs) were collected from healthy human volunteers (non-smoking donors who had not taken any drugs for at least 15 days prior to sampling, aged 18-35 years old) who provided written formal consent according to a protocol approved by the Ethics Committee in Research of Ceuma University (\#105/2014). Cells were isolated using the standard method of density-gradient centrifugation over Histopaque ${ }^{\circledR}-1119$. PBMCs were washed and suspended in a supplemented DMEN culture medium with added fetal bovine serum $10 \%, 100 \mu \mathrm{g} / \mathrm{ml}$ streptomycin, and $100 \mathrm{U} / \mathrm{ml}$ penicillin. PBMCs were plated in 96-well-plates $\left(2 \times 10^{5}\right.$ cells/well in 100 $\mu \mathrm{L})$ and added to $100 \mu \mathrm{L}$ of PBS or LGE at MIC, $1 / 2 \mathrm{MIC}$, $5 \mathrm{XMIC}$, or $10 \mathrm{XMIC}$. These sets were incubated at $37^{\circ} \mathrm{C}$ in a $5 \%$ $\mathrm{CO}_{2}$ atmosphere for $24 \mathrm{~h}$. At the end of the culture, an aliquot of 3-(4,5-dimethylthiazol-2-yl)-2,5-diphenyl tetrazolium bromide (MTT, $2 \mathrm{mg} / \mathrm{mL}$ in PBS) was added to each well, incubated for another $4 \mathrm{~h}$ at $37^{\circ} \mathrm{C}$ and protected from light. At this point, all of the solutions consisted of complete mediums, and the MTT was discarded. The formazan crystals were dissolved in DMSO $(100 \mu \mathrm{L})$, and the absorbance at $540 \mathrm{~nm}$ was determined using a spectrophotometer.

\section{Effects of LGE on Acrylic Resin}

Acrylic resin discs were immersed in distilled water (the control), LGE at MIC or LGE at 5XMIC. Discs were incubated at $37^{\circ} \mathrm{C}$ for 28 days. The immersion medium was changed daily, and the disc was rinsed in sterile distilled water and dried with absorbent paper. The tests were performed after $0,7,14,21$, and 28 days of immersion.

\section{Color Perception}

At each testing time, the discs were positioned under a silicon mold with an opening aimed to contact the samples to a spectrophotometer (EasyShade Advanced 4.0; Wilcos, Germany). This mold was used in order to accurately reposition and measure the colors of the disc surface. The color measurements were obtained using the CIE $\mathrm{L} * \mathrm{a} * \mathrm{~b} *$ color system following a previously established protocol (de Sousa Porta et al., 2015). The total color alteration $(\Delta \mathrm{E})$ was calculated using on the following equation: $\Delta \mathrm{E}^{*}=\left[\left(\Delta \mathrm{L}^{*}\right)^{2}+\left(\Delta \mathrm{a}^{*}\right)^{2}+\left(\Delta \mathrm{b}^{*}\right)^{2}\right]^{1 / 2}$.

\section{Surface Roughness}

At the same tested time, the discs were subjected to a surface roughness measurement (Surftest SJ-201P rugosimeter, Mitutoyo Corp.). For each sample, three readings were performed in the corresponding regions at $2.4 \mathrm{~mm}$ in length, a cutoff value of $0.8 \mathrm{~mm}$, and a speed of $0.5 \mathrm{~mm} / \mathrm{s}$. The roughness of each disc was calculated using the arithmetic mean of three measurements $(\mu \mathrm{m})$. The measurement of surface roughness $(\Delta \mathrm{Ra})$ was obtained based on the difference in roughness before and after immersion.

\section{Flexural Strength}

For the flexural strength assay, rectangular acrylic resin discs (65 $\times 10 \times 3 \mathrm{~mm}$ ) were fabricated, and a stainless matrix was used to standardize dimensions. The flexural strength $(S)$ was measured using a three-point bending test in a DL 2000 universal testing machine (EMIC, São José dos Pinhais, PR, Brazil) at a crosshead speed of $5 \mathrm{~mm} / \mathrm{min}$. The discs were subjected to flection until they fractured using a previously established protocol (Paranhos Hde et al., 2013). Flexural strength was calculated using the formula $S=3 P L / 2 b d^{2}$, where $S$ is flexural strength, $P$ is the peak load applied, $L$ is the span length, $b$ is the disc width, and $d$ is the disc thickness. The results were expressed in MPa.

\section{Statistical Analysis}

The results were statistically analyzed by the SAS/LAB software package (SAS Software, version 9.0; SAS Institute Inc., Cary, NC, USA). Assumptions about the equality of variances and the normal distribution of errors were checked. Data were transformed, as suggested by the software. Data concerning cell counts, metabolic activity, the viability of PBMC cells, and flexural strength were analyzed using a one-way ANOVA followed by Tukey's HSD test, in which the immersion treatment was treated as the study factor. Surface roughness and color alteration data were analyzed by two-way ANOVA for repeated measures followed by Tukey's HSD test, in which the treatment and immersion periods were considered to be study factors. The significance level was set to $5 \%$ for all tests.

\section{RESULTS}

The MIC and MFC of LGE observed for planktonic cells were $0.625 \mathrm{mg} / \mathrm{mL}$ and $2.5 \mathrm{mg} / \mathrm{mL}$, respectively, while fluconazole was 0.5 and $>64 \mu \mathrm{g} / \mathrm{mL}$.

It was observed that LGE exposure during biofilm development reduced the cell count compared to control group $(p<0.05)$. In addition, LGE at MIC was enough to reduce approximately $90 \%$ of biofilm cells $(p<0.0001)$, while LGE at 5 or 10XMIC achieved almost complete eradication (>99\%) of $C$. albicans biofilm (Figure 1A). For mature C. albicans biofilms, an $8 \mathrm{~h}$ exposure of LGE also had a significant effect, with lower cell counts $(p=0.001)$ and metabolic activity in all studied groups compared to the control group $(p<0.05)$, but with no statistical differences between the experimental groups and the studied variables $(p>0.05$, Figures 1B,C).

Representative microscope images of $C$. albicans biofilms were shown in Figure 2. The combined used of SYTO-9 and propidium iodide effectively labeled both live and dead yeast cells under different experimental conditions. Images showed that mature biofilms exposed to LGE tended to be less densely celled than the control group. Immersion in LGE at MIC, 5XMIC, and 10XMIC resulted in a large number of dead cells (stained in red) as well as a large number of black spaces, indicating the dispersion of biofilms.

If the PBMC culture in DMEN is the standard of $100 \%$ viability, it could be observed that LGE significantly reduced its viability $(p<0.05)$. However, when compared to the PBS group, which had no cytotoxic effects, the exposure of human cells to LGE at MIC resulted in similar viability $(p>0.05)$. Exposures to both lower and higher MICs resulted in significant reductions in cell viability, thereby demonstrating a discrete cytotoxicity $(p<$ 0.05 , Figure 3). 

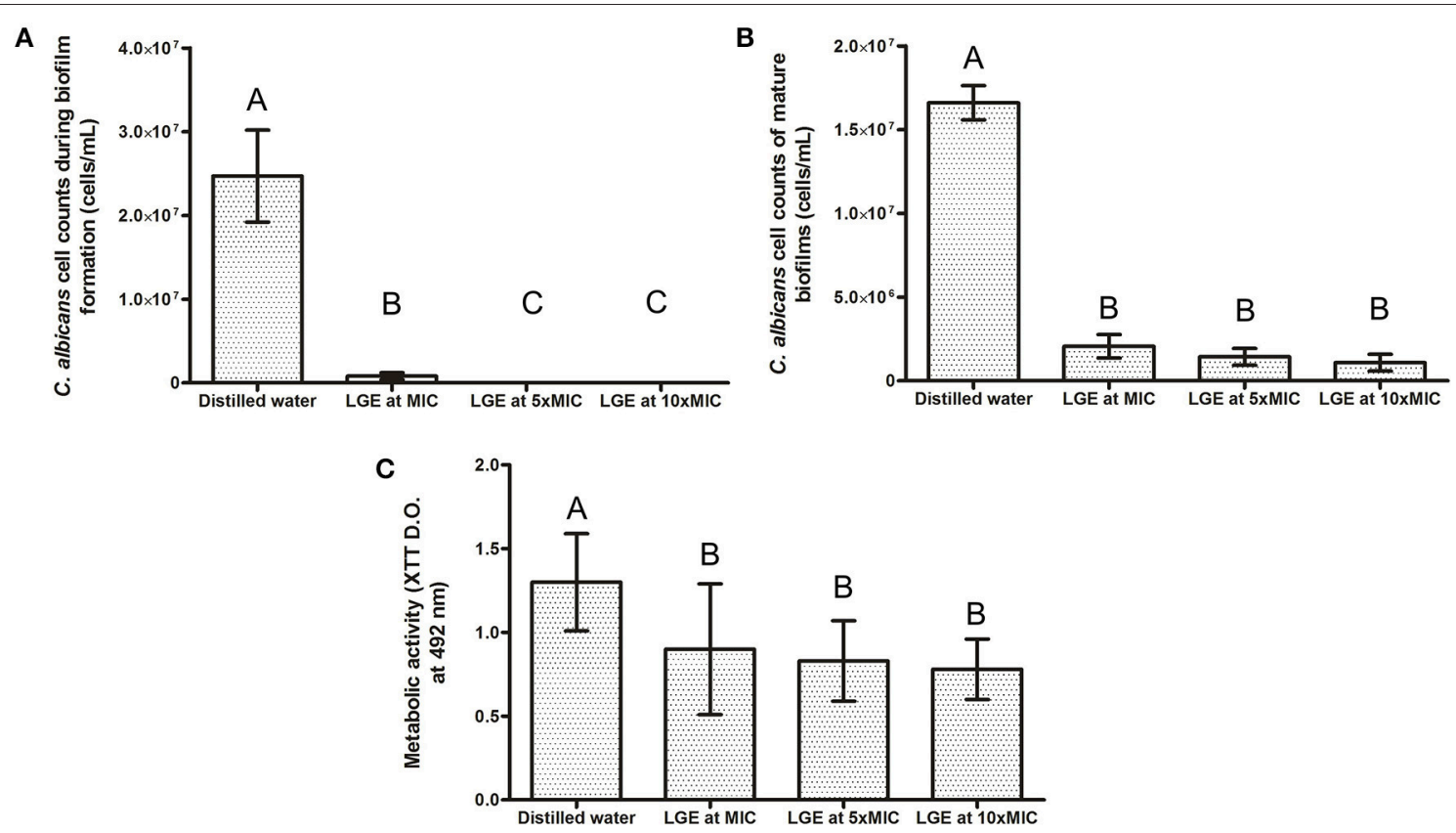

FIGURE 1 | Effect of LGE on C. albicans biofilm. (A) Number of cell counts when LGE was daily added to the fresh culture medium at different concentrations (MIC, 5XMIC, or 10XMIC) during $72 \mathrm{~h}$ biofilms formation; (B) Number of cell counts of a $72 \mathrm{~h}$ biofilm immersed for $8 \mathrm{~h}$ at different concentrations LGE (MIC, 5XMIC, or 10XMIC); (C) Metabolic activity of biofilms when mature biofilms were exposed to LGE. Different upper case letters represents statistically significant differences between groups (ANOVA one-way followed by Tukey test, $p<0.05$ ).
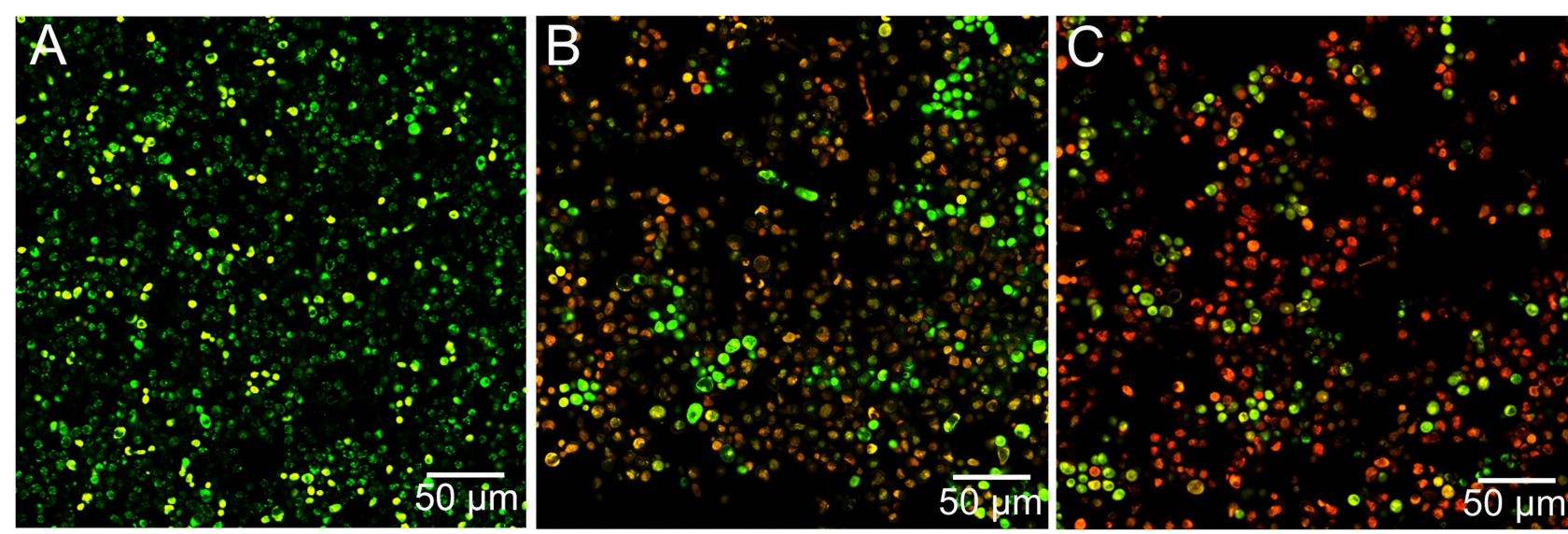

FIGURE 2 | Representative microscope images of mature $\mathbf{C}$. albicans biofilms after $\mathbf{8} \mathbf{h}$ of exposure to LEG. The combined use of SYTO-9 and propidium iodide effectively labeled both live and dead yeast cells under different experimental conditions: distilled water (A), LEG at MIC (B) or LEG at 5XMIC (C). Images showed that mature biofilms exposed to LGE tended to be less densely celled (B,C) than the control group (A). Immersion in LGE at MIC (B) and 5XMIC (B) resulted in a large number of dead cells as well as a large number of black spaces, indicating the dispersion of biofilms.

Regarding color stability, numerical variations were noticed in the CIEL*a* ${ }^{*}$ colorimetric system, but no significant differences between LGE at MIC and the control group were found for $\rho \mathrm{E}$ values (Table 1, $p>0.05$ ). However, after 14 days, a significant color alteration was detected when acrylic resin was immersed in LGE at 5XMIC. The roughness surface values of all evaluated periods of immersion in LGE demonstrated no statistically significant differences between the baseline means (Figure 4A, $p>0.05)$. Also, the mechanical property of flexural strength was not altered after LGE exposure in the different time periods that were tested (Figure 4B, $p>0.05$ ).

\section{DISCUSSION}

Nowadays, new compounds in all fields of fungal control have stimulated research into plant materials with antifungal 
properties (Ahmad and Beg, 2001; Duarte et al., 2005; Rios and Recio, 2005; Vieira et al., 2014). Cymbopogon citratus (DC) Stapf (Gramineae) is an herb known as lemongrass worldwide. The tea made from its leaves is often used in folk medicine as an antispasmodic, analgesic, anti-inflammatory, antipyretic, antimicrobial, diuretic, and sedative (Rios and Recio, 2005). In this study, the extract obtained from lemongrass was examined in vitro as an immersion solution to reduce the development of C. albicans biofilms on acrylic denture surfaces.

Susceptibility tests suggested that LGE showed fungistatic behavior at $0.625 \mathrm{mg} / \mathrm{mL}$ against $C$. albicans planktonic cells and fungicidal activity at $2.5 \mathrm{mg} / \mathrm{mL}$. Regarding MIC results, the following classification for the antimicrobial activity of plant products was proposed: strong inhibitors, MIC up to $0.5 \mathrm{mg} / \mathrm{mL}$; moderate inhibitors, MIC between 0.6 and $1.5 \mathrm{mg} / \mathrm{mL}$; and weak inhibitors, MIC above $1.6 \mathrm{mg} / \mathrm{mL}$ (Aligiannis et al., 2001). Regarding this classification, the LGE extract was considered to be a moderate inhibitor, which corroborates the results obtained in this study.

The antifungal effects of lemongrass in several formulations (e.g., citral, vapor phase, essential oil, or hydro-alcoholic extracts) are well-established, and the present data corroborates the literature (Abe et al., 2003; Silva Cde et al., 2008; Irkin and Korukluoglu, 2009; Korenblum et al., 2013; Amornvit et al., 2014; Tadtong et al., 2014). Considering that most Candida cells in the oral cavity are associated with biofilms, which differ substantially from planktonic cells due to their higher antifungal resistance

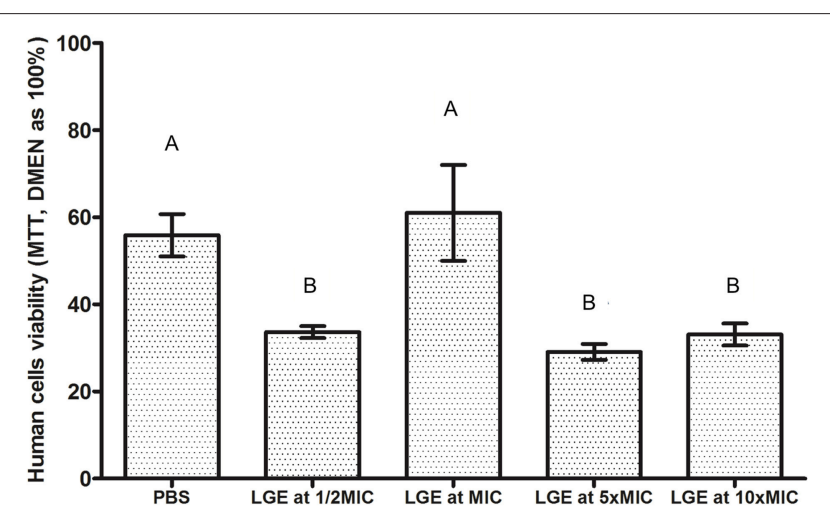

FIGURE 3 | PBMC cells viability after exposure to different LGE concentrations. Different upper case letters represents statistically significant differences between groups (ANOVA one-way followed by Tukey test, $p<0.05)$
(Ramage et al., 2014), investigating the behavior of cells organized in biofilms when they are exposed to LGE is of the utmost importance.

As a starting point, it was observed the effects of LGE during biofilm formation. Thus, LGE was added to a culture medium at different concentrations, and cell quantification was performed after $72 \mathrm{~h}$ of development. A more significant reduction was observed in experimental groups at 5XMIC, a concentration sufficient for eliminating biofilm cells. The fact that biofilms were grown in the constant presence of LGE could lead the extract to exert a toxic effect. Several mechanisms have been proposed to explain vegetal antifungal activity, including disruption of the fungi cell structure, thereby causing leakage and cell death; blockage of membrane synthesis; and inhibition of spore germination, fungal proliferation, and cellular respiration (Wilkinson and Cavanagh, 2005). Therefore, investigating the chemical composition of lemongrass allow us to suggest that the presence of aldehydes, which are known for their antibacterial and fungitoxic properties (Wilkinson and Cavanagh, 2005; Khan and Ahmad, 2012; Machado et al., 2012), could explain the outcomes that were achieved.

We investigated the effects of LGE in a $72 \mathrm{~h}$-mature biofilm developed on an acrylic denture surface in order to simulate an overnight denture soaking period of $8 \mathrm{~h}$. Distilled water was employed as a control group, since it is indicated for denture immersion during sleep. These results demonstrated that $8 \mathrm{~h}$ of immersion in LGE at MIC were sufficient to reduce the metabolic activity and number of cells compared to the control group. This decrease in a short exposure time could also be explained by the presence of oxygenated monoterpenes aldehydes in the vegetal composition. Citral (3,7-dimethyl-2,6-octadienal) is the major monoterpene present in lemongrass (65-85\%), and it is a mixture of two isomeric aldehydes, geranial (trans-citral, citral A), and neral (cis-citral, citral B), that possess significant antimicrobial activity (Machado et al., 2012), as discussed earlier. Besides this, lemongrass could also contain other antifungal monoterpene hydrocarbons, such as camphene and limonene (Tyagi and Malik, 2010). The fungicidal effects of LGE could be confirmed by the increased number of dead cells observed in microscopic images. Future investigations should take into account the exact molecular mechanisms that explain the death of fungal cells in the presence of LGE.

Maintenance of human cell viability after LGE exposure should be determined to ensure its safe use in future clinical studies. Though the inflammation observed in CADS is mainly characterized by lymphocytes and monocytes (Sinha et al., 2014),

TABLE 1 | Degree of color difference $(\rho E)$ of the acrylic surface after LGE exposure in different periods of time $(n=9)$.

\begin{tabular}{lcccc}
\hline & $\mathbf{7}$ days & $\mathbf{1 4}$ days & $\mathbf{2 1}$ days & $\mathbf{2 8}$ days \\
\hline Distilled water & $3.24 \pm 1.41(\mathrm{~A}, \mathrm{a})$ & $3.33 \pm 1.82(\mathrm{~A}, \mathrm{a})$ & $3.25 \pm 1.52(\mathrm{~A}, \mathrm{a})$ & $3.22 \pm 0.71(\mathrm{~A}, \mathrm{a})$ \\
LEG at MIC & $3.36 \pm 0.54(\mathrm{~A}, \mathrm{a})$ & $3.05 \pm 1.53(\mathrm{~A}, \mathrm{a})$ & $3.15 \pm 1.86(\mathrm{~A}, \mathrm{a})$ & $3.25 \pm 1.05(\mathrm{~A}, \mathrm{a})$ \\
LEG at 5 XMIC & $3.26 \pm 1.38(\mathrm{~A}, \mathrm{a})$ & $3.76 \pm 0.97(\mathrm{~B}, \mathrm{~b})$ & $3.88 \pm 0.27(\mathrm{~B}, \mathrm{~b})$ & $4.05 \pm 0.61(\mathrm{~B}, \mathrm{~b})$ \\
\hline
\end{tabular}

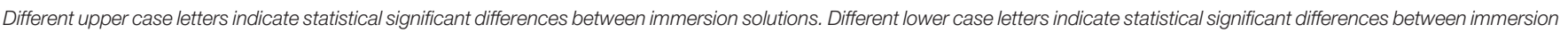
periods (ANOVA two-way for repeated measures followed by Tukey test, $p<0.05$ ). 
A

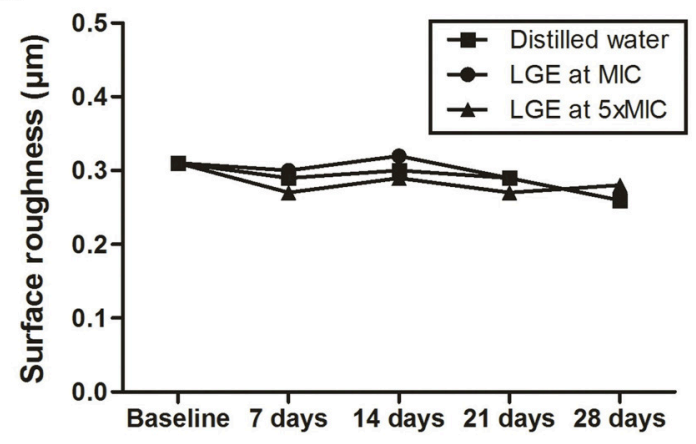

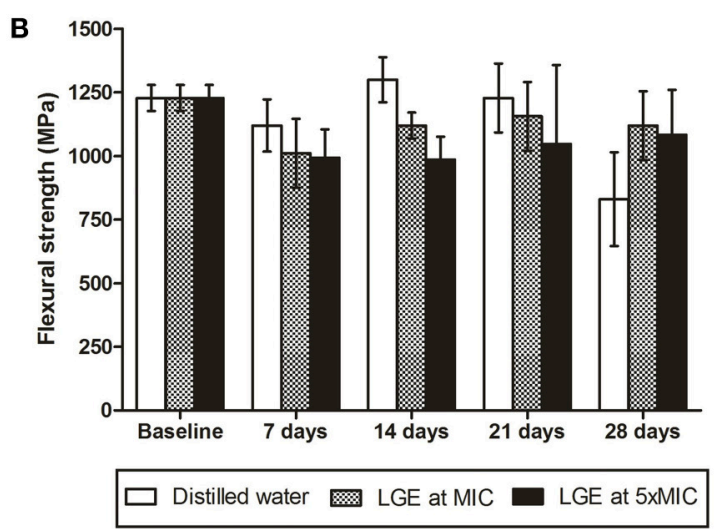

FIGURE 4 | Analysis of acrylic resin properties after immersion in LGE at different concentrations. (A) Surface roughness and (B) flexural strength after immersion in LGE at different time-points. There were no statistical differences between groups or periods of immersion (ANOVA two-way followed by Tukey test, $p<0.05)$.

assessing the cytotoxic potential of LGE to target these cells is relevant. This study demonstrated that LGE at MIC provided a cellular viability similar to PBS (the control group), although this solution is well-known to be non-toxic to human cells due to its osmotic capacity. Although concentrations higher than MIC did not completely cause cell death, a discrete cytotoxicity could be observed. Thus, according to our results, MIC seems to be a concentration that ensures that satisfactory biofilm control does not result in significant damage to host cells. Nevertheless, cell types present in oral mucosa, such as keratinocytes and fibroblasts, should be considered in further research.

It has been shown that immersion in certain chemical solutions can affect the color, roughness and strength of denture base resins, which are all directly related to longevity and esthetic (Felipucci et al., 2011; Moffa et al., 2011; Paranhos Hde et al., 2013; Savabi et al., 2013; de Sousa Porta et al., 2015). Although 28 days of LGE immersion seems to be a short period of time compared to the lifespan of a denture, we understand that constant exposure to the solution (changed every day) may significantly age the acrylic matrix, thereby creating a challenging situation for the tested discs. Also, based on the similar microbiological and cytotoxic results of LGE 5XMIC and LGE 10XMIC, the higher concentration was excluded from substratum assays.

Color stability after LGE immersion was evaluated using the CIEL*a*b* colorimetric system, a uniform three-dimensional system that has been widely used to determine chromatic differences by translating their combinations into mathematical data. In this system, color alteration $(\rho \mathrm{E})$ is defined as the relative color change between repeated color evaluations. Given that a color difference of $<3.7$ is reported to be clinically imperceptible (Moon et al., 2014) the immersion of acrylic resin in LEG at MIC did not cause a visible color alteration in this study. This result seems very interesting because the main disadvantage of conventional chemical cleansers, such as sodium hypochlorite, is their whitening properties when used for prolonged periods
(Moffa et al., 2011; Savabi et al., 2013; Moon et al., 2014). Actually, the LGE at 5XMIC was sufficient to stain the substratum surface after 14 days of immersion. The highest concentration of active compounds in this experimental group, which are green in color, may impregnate the acrylic matrix and cause this alteration.

The surface roughness is an important factor of the adherence and entrapment of microorganisms on acrylic denture materials. Therefore, it is crucial that solutions do not alter such properties, since rougher surfaces could increase biofilm formation (Paranhos Hde et al., 2013). Also, it is undesirable for a solution to interfere with the substratum's mechanical properties. If a treatment negatively affects the resins by decreasing their strength, a greater incidence of denture fractures might occur both outside and inside the mouth (Paranhos Hde et al., 2013; de Sousa Porta et al., 2015). In this study, the immersion of acrylic resin in LGE did not lead to significant changes in surface roughness or flexural strength, which means that in experimental conditions, the solution was safe to use.

\section{CONCLUSION}

The immersion of denture surfaces in lemongrass extract (LGE) was effective in reducing $C$. albicans biofilms without affecting mechanical and physical substratum properties. Furthermore, human cell outcomes showed that the concentration of the tested extract was effective and safe to use. In addition, these results demonstrated the potential to use lemongrass, as valid disinfectant either pre- or post-biofilm formation, as an alternative substance for controlling C. albicans biofilms development on denture surfaces.

\section{AUTHOR CONTRIBUTIONS}

contributed to conception or design: PM, LC, MP, ED, EM, $\mathrm{MD}, \mathrm{RT}$, and LG. contributed to acquisition, analysis, or interpretation: PM, LC, MP, RT, and LG. drafted the manuscript: 
PM, MP, ED, MD, and LG. critically revised the manuscript: PM, LC, MP, ED, EM, MD, RT, and LG. gave final approval: PM, LC, MP, ED, EM, MD, RT, and LG. Agrees to be accountable for all aspects of work ensuring integrity and accuracy: PM, LC, MP, ED, EM, MD, RT, and LG.

\section{REFERENCES}

Abe, S., Sato, Y., Inoue, S., Ishibashi, H., Maruyama, N., Takizawa, T., et al. (2003). [Anti-Candida albicans activity of essential oils including Lemongrass (Cymbopogon citratus) oil and its component, citral]. Nihon Ishinkin Gakkai Zasshi 44, 285-291. doi: 10.3314/jimm.44.285

Ahmad, I., and Beg, A. Z. (2001). Antimicrobial and phytochemical studies on 45 Indian medicinal plants against multi-drug resistant human pathogens. J. Ethnopharmacol. 74, 113-123. doi: 10.1016/S0378-8741(00)00335-4

Aligiannis, N., Kalpoutzakis, E., Mitaku, S., and Chinou, I. B. (2001). Composition and antimicrobial activity of the essential oils of two Origanum species. J. Agric. Food Chem. 49, 4168-4170. doi: 10.1021/jf001494m

Amornvit, P., Choonharuangdej, S., and Srithavaj, T. (2014). Lemongrassincorporated tissue conditioner against Candida albicans culture. J. Clin. Diagn. Res. 8, ZC50-ZC52. doi: 10.7860/JCDR/2014/8378.4607

Boukhatem, M. N., Ferhat, M. A., Kameli, A., Saidi, F., and Kebir, H. T. (2014). Lemon grass (Cymbopogon citratus) essential oil as a potent anti-inflammatory and antifungal drugs. Libyan J. Med. 9:25431. doi: 10.3402/ljm.v9.25431

CLSI (2008) Reference Method for Broth Dilution Antifungal Susceptibility Testing of Yeasts, Approved Standard. CLSI Document M27-A3. Pennysylvania, PA: CLSI.

da Silva, W. J., Seneviratne, J., Parahitiyawa, N., Rosa, E. A., Samaranayake, L. P., and Del Bel Cury, A. A. (2008). Improvement of XTT assay performance for studies involving Candida albicans biofilms. Braz. Dent. J. 19, 364-369. doi: 10.1590/S0103-64402008000400014

de Sousa Porta, S. R., de Lucena-Ferreira, S. C., da Silva, W. J., and Del Bel Cury, A. A. (2015). Evaluation of sodium hypochlorite as a denture cleanser: a clinical study. Gerodontology. 32, 260-266. doi: 10.1111/ger.12104

Duarte, M. C., Figueira, G. M., Sartoratto, A., Rehder, V. L., and Delarmelina, C. (2005). Anti-Candida activity of Brazilian medicinal plants. J. Ethnopharmacol. 97, 305-311. doi: 10.1016/j.jep.2004.11.016

Felipucci, D. N., Davi, L. R., Paranhos, H. F., Bezzon, O. L., Silva, R. F., and Pagnano, V. O. (2011). Effect of different cleansers on the surface of removable partial denture. Braz. Dent. J. 22, 392-397. doi: 10.1590/S010364402011000500008

Gendreau, L., and Loewy, Z. G. (2011). Epidemiology and etiology of denture stomatitis. J. Prosthodont. 20, 251-260. doi: 10.1111/j.1532-849X.2011.00698.x

Glass, R. T., Conrad, R. S., Bullard, J. W., Goodson, L. B., Mehta, N., Lech, S. J., et al. (2010). Evaluation of microbial flora found in previously worn prostheses from the Northeast and Southwest regions of the United States. J. Prosthet. Dent. 103, 384-389. doi: 10.1016/S0022-3913(10)60083-2

Gonçalves, L. M., Del Bel Cury, A. A., de Vasconcellos, A. A., Cury, J. A., and da Silva, W. J. (2015). Confocal analysis of the exopolysaccharide matrix of Candida albicans biofilms. J. Investig. Clin. Dent. 6, 179-185. doi: 10.1111/jicd.12093

Gonçalves, L. M., Del Bel Cury, A. A., Sartoratto, A., Garcia Rehder, V. L., and Silva, W. J. (2012). Effects of undecylenic acid released from denture liner on Candida biofilms. J. Dent. Res. 91, 985-989. doi: 10.1177/0022034512458689

Irkin, R., and Korukluoglu, M. (2009). Effectiveness of Cymbopogon citratus L. essential oil to inhibit the growth of some filamentous fungi and yeasts. J. Med. Food 12, 193-197. doi: 10.1089/jmf.2008.0108

Khan, M. S., and Ahmad, I. (2012). Biofilm inhibition by Cymbopogon citratus and Syzygium aromaticum essential oils in the strains of Candida albicans. J. Ethnopharmacol. 140, 416-423. doi: 10.1016/j.jep.2012.01.045

Korenblum, E., Regina de Vasconcelos Goulart, F., de Almeida Rodrigues, I., Abreu, F., Lins, U., Alves, P. B., et al. (2013). Antimicrobial action and anticorrosion effect against sulfate reducing bacteria by lemongrass (Cymbopogon citratus) essential oil and its major component, the citral. AMB Exp. 3:44. doi: 10.1186/2191-0855-3-44

\section{ACKNOWLEDGMENTS}

The authors would like to thank Foundation for Research and Scientific Development of Maranhão (FAPEMA) for the financial support (PAEDT-36-2014 and UNIVERSAL-604-14).

Krom, B. P., Kidwai, S., and Ten Cate, J. M. (2014). Candida and other fungal species: forgotten players of healthy oral microbiota. J. Dent. Res. 93, 445-451. doi: $10.1177 / 0022034514521814$

Lalla, R. V., and Dongari-Bagtzoglou, A. (2014). Antifungal medications or disinfectants for denture stomatitis. Evid. Based Dent. 15, 61-62. doi: 10.1038/sj.ebd.6401032

Lucena-Ferreira, S. C., Cavalcanti, I. M., and Cury, A. A. (2013). Efficacy of denture cleansers in reducing microbial counts from removable partial dentures: a short-term clinical evaluation. Braz. Dent. J. 24, 353-356. doi: 10.1590/01036440201302183

Lucena-Ferreira, S. C., Ricomini-Filho, A. P., Silva, W. J., Cury, J. A., and Cury, A. A. (2014). Influence of daily immersion in denture cleanser on multispecies biofilm. Clin. Oral Investig. 18, 2179-2185. doi: 10.1007/s00784-014-1210-9

Machado, M., Pires, P., Dinis, A. M., Santos-Rosa, M., Alves, V., Salgueiro, L., et al. (2012). Monoterpenic aldehydes as potential anti-Leishmania agents: activity of Cymbopogon citratus and citral on L. infantum, L. tropica and L. major. Exp. Parasitol. 130, 223-231. doi: 10.1016/j.exppara.2011.12.012

Moffa, E. B., Giampaolo, E. T., Izumida, F. E., Pavarina, A. C., Machado, A. L., and Vergani, C. E. (2011). Colour stability of relined dentures after chemical disinfection. A randomised clinical trial. J. Dent. 39(Suppl. 3), e65-e71. doi: 10.1016/j.jdent.2011.10.008

Moon, A., Powers, J. M., and Kiat-Amnuay, S. (2014). Color stability of denture teeth and acrylic base resin subjected daily to various consumer cleansers. J. Esthet. Restor. Dent. 26, 247-255. doi: 10.1111/jerd.12109

Moura, J. S., da Silva, W. J., Pereira, T., Del Bel Cury, A. A., and Rodrigues Garcia, R. C. (2006). Influence of acrylic resin polymerization methods and saliva on the adherence of four Candida species. J. Prosthet. Dent. 96, 205-211. doi: 10.1016/j.prosdent.2006.07.004

Nett, J. E. (2014). Future directions for anti-biofilm therapeutics targeting Candida. Expert Rev. Anti Infect. Ther. 12, 375-382. doi: 10.1586/14787210.2014.885838

Padilha, D. M., Hugo, F. N., Hilgert, J. B., and Dal Moro, R. G. (2007). Hand function and oral hygiene in older institutionalized Brazilians. J. Am. Geriatr. Soc. 55, 1333-1338. doi: 10.1111/j.1532-5415.2007.01278.x

Paranhos Hde, F., Peracini, A., Pisani, M. X., Oliveira Vde, C., de Souza, R. F., and Silva-Lovato, C. H. (2013). Color stability, surface roughness and flexural strength of an acrylic resin submitted to simulated overnight immersion in denture cleansers. Braz. Dent. J. 24, 152-156. doi: 10.1590/0103-64402 01302151

Pellizzaro, D., Polyzois, G., Machado, A. L., Giampaolo, E. T., Sanita, P. V., and Vergani, C. E. (2012). Effectiveness of mechanical brushing with different denture cleansing agents in reducing in vitro Candida albicans biofilm viability. Braz. Dent. J. 23, 547-554. doi: 10.1590/S0103-644020120005 00013

Ramage, G., Robertson, S. N., and Williams, C. (2014). Strength in numbers: antifungal strategies against fungal biofilms. Int. J. Antimicrob. Agents 43, 114-120. doi: 10.1016/j.ijantimicag.2013.10.023

Ríos, J. L., and Recio, M. C. (2005). Medicinal plants and antimicrobial activity. $J$. Ethnopharmacol. 100, 80-84. doi: 10.1016/j.jep.2005.04.025

Savabi, O., Attar, K., Nejatidanesh, F., Goroohi, H., and Badrian, H. (2013). Effect of different chemical disinfectants on the flexural strength of heat-polymerized acrylic resins. Eur. J. Prosthodont. Restor. Dent. 21, 105-108.

Silva Cde, B., Guterres, S. S., Weisheimer, V., and Schapoval, E. E. (2008) Antifungal activity of the lemongrass oil and citral against Candida spp. Braz. J. Infect. Dis. 12, 63-66. doi: 10.1590/S1413-867020080001 00014

Sinha, S., Jothiramajayam, M., Ghosh, M., and Mukherjee, A. (2014). Evaluation of toxicity of essential oils palmarosa, citronella, lemongrass and vetiver in human lymphocytes. Food Chem. Toxicol. 68, 71-77. doi: 10.1016/j.fct.2014. 02.036 
Tadtong, S., Watthanachaiyingcharoen, R., and Kamkaen, N. (2014). Antimicrobial constituents and synergism effect of the essential oils from Cymbopogon citratus and Alpinia galanga. Nat. Prod. Commun. 9, 277-280.

Taff, H. T., Mitchell, K. F., Edward, J. A., and Andes, D. R. (2013). Mechanisms of Candida biofilm drug resistance. Future Microbiol. 8, 1325-1337. doi: $10.2217 /$ fmb. 13.101

Tan, C. M., Tsoi, J. K., Seneviratne, C. J., and Matinlinna, J. P. (2014). Evaluation of the Candida albicans removal and mechanical properties of denture acrylics cleaned by a low-cost powered toothbrush. J. Prosthodont. Res. 58, 243-251. doi: 10.1016/j.jpor.2014.06.002

Taweechaisupapong, S., Ngaonee, P., Patsuk, P., Pitiphat, W., and Khunkitti, W. (2012). Antibiofilm activity and post antifungal effect of lemongrass oil on clinical Candida dubliniensis isolate. South Afr. J. Bot. 78, 37-43. doi: 10.1016/j.sajb.2011.04.003

Tyagi, A. K., and Malik, A. (2010). Liquid and vapour-phase antifungal activities of selected essential oils against Candida albicans: microscopic observations and chemical characterization of Cymbopogon citratus. BMC Complement. Altern. Med. 10:65. doi: 10.1186/1472-6882-10-65
Vieira, D. R., Amaral, F. M., Maciel, M. C., Nascimento, F. R., Liberio, S. A., and Rodrigues, V. P. (2014). Plant species used in dental diseases: ethnopharmacology aspects and antimicrobial activity evaluation. J. Ethnopharmacol. 155, 1441-1449. doi: 10.1016/j.jep.2014.07.021

Wilkinson, J. M., and Cavanagh, H. M. (2005). Antibacterial activity of essential oils from Australian native plants. Phytother. Res. 19, 643-646. doi: $10.1002 /$ ptr. 1716

Conflict of Interest Statement: The authors declare that the research was conducted in the absence of any commercial or financial relationships that could be construed as a potential conflict of interest.

Copyright (c) 2016 Madeira, Carvalho, Paschoal, de Sousa, Moffa, da Silva, Tavarez and Gonçalves. This is an open-access article distributed under the terms of the Creative Commons Attribution License (CC BY). The use, distribution or reproduction in other forums is permitted, provided the original author (s) or licensor are credited and that the original publication in this journal is cited, in accordance with accepted academic practice. No use, distribution or reproduction is permitted which does not comply with these terms. 